\title{
STRUCTURE AND MECHANICAL BEHAVIOR OF ADDITIVE MANUFACTURED FUSED DEPOSITION MODELING ABS
}

\author{
A. Solomon ${ }^{1}$, Y. Rosenthalin, D. Ashkenazi2*, A. Stern ${ }^{1,3}$ \\ ${ }^{1}$ School of Mechanical Engineering, Afeka Academic College of Engineering, Tel Aviv, 69107, Israel \\ ${ }^{2}$ School of Mechanical Engineering, Tel Aviv University, Ramat Aviv 6997801, Israel \\ ${ }^{3}$ Department of Materials Engineering, Ben-Gurion University of the Negev, Beer Sheva 8410501, Israel \\ *Corresponding author's e-mail address: dana@eng.tau.ac.il
}

\begin{abstract}
One of the most important Additive Manufacturing (AM) technologies is the Fused Deposition Modeling (FDM) technology, suitable for various engineering applications which is currently used with many types of thermoplastic materials including ABS. AM-FDM printed ABS possesses an inherent capacity for property modifications as a function of printing parameters. The main goals of this study were to characterize experimentally the mechanical and structural properties of printed ABS specimens; as well as to reach an expression that will allow us to estimate the strength of the AM-FDM printed ABS for different printing parameters, prior to the printing process. In this experimental study, the mechanical and structural characterization of AM-FDM ABS material was performed by visual non-destructive testing inspection, mechanical testing, and light microscopy (LM) investigation. The three-point bend flexural test results revealed the mechanical properties as well as the fracture surface, according to build-on (coupon) specimens' dimensions and build-strategies. The results of this study provide preliminary quantitative estimates for the mechanical significant properties, as a function of some AM-FDM process variables for the ABS material. Parameter coefficients were defined to calculate the estimated strength of the printed ABS. They are chosen according to the desired printing parameters, and then multiplied by the highest average strength achieved for the $X$ or $Z$ direction bending tests specimens to achieve the estimated strength. The parameter coefficients were used to estimate the flexural strength of AM-FDM ABS specimens pertaining to a different $R \& D$ project; a decent agreement between the experimental data and the calculated results was obtained.
\end{abstract}

KEYWORDS: ABS, additive manufacturing, flexural strength expression, FDM, fracture surface, mechanical properties, three-point bend flexural test.

\section{ACKNOWLEDGEMENTS}

The research was supported by the Afeka Academic College of Engineering, to whom the authors are grateful. Thanks are due to V. Palei, S. Maman, and A. Ulanov, Afeka Academic College of Engineering, for their engineering assistance. Thanks also go to fellow students N. Dresler and E. Shprontz from the Department of Mechanical Engineering, Afeka Academic College of Engineering, for their great assistance and technical support. The authors are also grateful to Prof. J. Peleg of Middlesex County College, New Jersey, USA, for the English editing.

\section{REFERENCES}

[1] Wong K. V., Hernandez A., A review of additive manufacturing, ISRN Mechanical Engineering, 2012, pp. 1-11.

[2] Singh S., Ramakrishna S., Singh R., Material issues in additive manufacturing: A review, Journal of Manufacturing Processes 25, 2017, pp. 185-200.

[3] Rios O., Carter W., Post B., Lloyd P., Fenn D., Kutchko C., Rock R., Olson K., Compton B., 3D printing via ambient reactive extrusion, Materials Today Communications, 15, 2018, pp.333-336.

[4] Ngo T. D., Kashani A., Imbalzano G., Nguyen K. T., Hui D., Additive manufacturing (3D printing): A review of materials, methods, applications and challenges, Composites Part B: Engineering 143, 2018, pp. 172-196.

[5] Costabile G., Fera M., Fruggiero F., Lambiase A., Pham D., Cost models of additive manufacturing: A literature review, International Journal of Industrial Engineering Computations 8.2, 2017, pp. 263-283. 
[6] Li G., Zhao J., Wu W., Jiang J., Wang B., Jiang H., Fuh J. Y. H., Effect of ultrasonic vibration on mechanical properties of 3D printing non-crystalline and semi-crystalline polymers, Materials 11.5, 2018, pp. 826-839.

[7] Balderrama-Armendariz C. O., MacDonald E., Espalin D., Cortes-Saenz D., Wicker R., Maldonado-Macias A., Torsion analysis of the anisotropic behavior of FDM technology, The International Journal of Advanced Manufacturing Technology 96, 2018, pp. 307-317.

[8] Turner B. N., Strong R., Gold S. A., A review of melt extrusion additive manufacturing processes: I. Process design and modeling, Rapid Prototyping Journal 20.3, 2014, pp. 192-204.

[9] Turner B. N., Gold S. A., A review of melt extrusion additive manufacturing processes: II. Materials, dimensional accuracy, and surface roughness, Rapid Prototyping Journal 21.3, 2015, pp. 250-261.

[10] Shabat D., Rosenthal Y., Ashkenazi D., Stern A., Mechanical and structural characteristics of fused deposition modeling ABS material, The Annals of "Dunarea De Jos" University of Galati. Fascicle XII: Welding Equipment and Technology 28, 2017, pp.16-24.

[11] Gajdo I., Slota J., Influence of printing conditions on structure in FDM prototypes, Technical Gazette 20.2, 2013, pp. 231-236.

[12] Bochmann L., Bayley C., Helu M., Transchel R., Wegener K., Dornfeld D., Understanding error generation in fused deposition modeling, Surface Topography: Metrology and Properties 3.1, 2015, pp. 1-9.

[13] Jin Y. A., He Y., Fu J. Z., Gan W. F. Lin, Z. W., Optimization of tool-path generation for material extrusion-based additive manufacturing technology, Additive Manufacturing 1, 2014, pp. 32-47.

[14] Wu W., Geng P., Li G., Zhao D., Zhang H., Zhao J., Influence of layer thickness and raster angle on the mechanical properties of 3Dprinted PEEK and a comparative mechanical study between PEEK and ABS, Materials 8.9, 2015, pp. 5834-5846.

[15] Magalhães L. C., Volpato N., Luersen M., Build parameters influence on FDM parts mechanical behavior, 21st Brazilian Congress of Mechanical Engineering, October 2011, Natal, RN, Brazil, pp. 24-28.

[16] Tymrak B. M., Kreiger M., Pearce J. M., Mechanical properties of components fabricated with open-source 3-D printers under realistic environmental conditions, Materials \& Design 58, 2014, pp. 242-246.

[17] Durgun I., Ertan R., Experimental investigation of FDM process for improvement of mechanical properties and production cost, Rapid Prototyping Journal 20.3, 2014, pp. 228-235.

[18] Hossain M. S., Ramos, J., Espalin D., Perez M., Wicker R., Improving tensile mechanical properties of FDM-manufactured specimens via modifying build parameters, In International Solid Freeform Fabrication Symposium: An Additive Manufacturing Conference, 2013, Austin, TX, pp. 380-392.

[19] Qureshi A. J., Mahmood S., Wong W. L. E., Talamona D., Design for Scalability and Strength Optimisation for components created through FDM process, Proceedings of the 20th International Conference on Engineering Design 6, 2015, pp. 255-266.

[20] Górski F., Wichniarek R., Kuczko W., Zawadzki P., Buń P., Strength of ABS parts produced by Fused Deposition Modelling technology-a critical orientation problem, Advances in Science and Technology Research Journal 9.26, 2015, pp. 12-19.

[21] Vairis A., Petousis M., Vidakis N., Savvakis K., On the Strain Rate Sensitivity of ABS and ABS Plus Fused Deposition Modeling Parts, Journal of Materials Engineering and Performance 25.9, 2016, pp. 3558-3565.

[22] Torrado A. R., Shemelya C. M., English J. D., Lin Y., Wicker R. B., Roberson D. A., Characterizing the effect of additives to ABS on the mechanical property anisotropy of specimens fabricated by material extrusion 3D printing, Additive Manufacturing 6, 2015, pp. 16-29.

[23] Torrado A. R., Roberson D. A., Failure analysis and anisotropy evaluation of 3D-printed tensile test specimens of different geometries and print raster patterns, Journal of Failure Analysis and Prevention 16.1,2016, pp. 154-164.

[24] Zhang Y., Chou, K., A parametric study of part distortions in fused deposition modelling using three-dimensional finite element analysis, Proceedings of the Institution of Mechanical Engineers, Part B: Journal of Engineering Manufacture 222(8), 2008, pp. 959-968.

[25] Siqueiros J. G., Schnittker K., Roberson D. A., ABS-maleated SEBS blend as a 3D printable material, Virtual and Physical Prototyping 11.2, 2016, pp. 123-131.

[26] Perez A. R. T., Roberson D. A., Wicker R. B., Fracture surface analysis of 3D-printed tensile specimens of novel ABS-based materials, Journal of Failure Analysis and Prevention 14.3, 2014, pp. 343-353.

[27] Berger A., Sharon Y., Ashkenazi D., Stern A., Test artifact for additive manufacturing technology: FDM and SLM preliminary results, Annals of "Dunarea De Jos" University of Galati Fascicle XII, Welding Equipment and Technology 27, 2016, pp. 29-37. 